\title{
Social Validity evaluation of the FRIENDS for Life Program with Mexican Children
}

\author{
Julia Gallegos-Guajardo ${ }^{1}$, Norma Alicia Ruvalcaba-Romero ${ }^{2}$, Martha Garza-Tamez ${ }^{3} \&$ Diana Villegas-Guinea ${ }^{4}$ \\ ${ }^{1}$ Center for Treatment and Research on Anxiety (CETIA), University of Monterrey, Mexico \\ ${ }^{2}$ Department of Mental Health Clinics, University of Guadalajara, Mexico \\ ${ }^{3}$ Department of Psychology, Autonomous University of Nuevo Leon, Mexico \\ ${ }^{4}$ University Complutense of Madrid, Spain \\ Correspondence: Julia Gallegos-Guajardo. Rio Amazonas 132 Ote. Local 9-I , San Pedro Garza García, Nuevo \\ León, Mexico. C.P. 66220. Tel: 1-52-81-15-22-99-08. E-mail: juliagallegos@ centrocies.com.mx
}

Received: February 10, 2013 Accepted: February 25, 2013 Available online: March 9, 2013

doi:10.11114/jets.v1i1.90 URL: http://dx.doi.org/10.11114/jets.v1i1.90

\begin{abstract}
This study is the first social validity evaluation of the Spanish version of the FRIENDS for Life program with Mexican children. FRIENDS for Life is a cognitive-behavioral intervention aimed at increasing social and emotional competence and decreasing anxiety and depressive symptoms in children. The program is designed to empower children and families by teaching relaxation techniques, coping and interpersonal skills, and positive thinking. Participants were 498 students, ages 9 to 11. Upon completion of the program, students, parents, and teachers were surveyed regarding their perceptions on the utility and enjoyability, and their global satisfaction. Results indicate that students, parents, and teachers evaluate the program as helpful and enjoyable. Gender differences were found, girls reported the program as more useful and enjoyable than boys. The skill that students and parents found more useful was changing negative thoughts into positive, and positive correlations were also found between level of satisfaction and outcome measures.
\end{abstract}

Keywords: prevention, anxiety, depression , Mexican children, social validity

\section{Introduction}

Effective intervention programs are those that are not only cost and time effective but also involve the active participation of all consumers. It is important for applied researchers to know if the behavioral goals selected for study are significant, if the procedures are appropriate, and if the effects produced are important for clients and society; in other words, to know how participants perceive the intervention termed as "social validity"(Fawcett, 1991).

Wolf (1978) talks about social validity as a subjective measurement that is important to consider in behavioral analysis; he argues that "social importance is a subjective value judgment that only society was qualified to make" (Wolf, 1978; pp. 206-207). If the purpose is to evaluate social importance, society would need to validate the interventions on three levels: a) the social significance of the goals, b) the social appropriateness of the procedures; that means that we need to know if the participants, caregivers and other consumers consider that the intervention is acceptable or not, and c) the social importance of the effects; that is, if consumers are satisfied with the results (Wolf, 1978).

It is better to think of social validity as a process, rather than a result or outcome, so it can be assessed at several stages in the intervention process (Fawcett, 1991). The level of satisfaction with intervention procedures is usually assessed by using self-report questionnaires that should include the different elements that might contribute to the variance in satisfaction rating (Foster \& Mash; as cited in Barrett, Shortt, Fox, \& Wescombe, 2001). Schwartz and Baer (1991) suggested evaluating a specific component and also an overall rating of satisfaction. There is a need for more research to understand the relationship between intervention acceptability and outcome.

All interventions should ideally include a social validity evaluation, especially those designed to work in the areas of social and emotional development and prevention of anxiety and depression. Prevention of anxiety and depressive disorders is very important as these are common problems among children that, if left untreated, may 
lead to a broad range of negative consequences for the child and his or her family (Kashani \& Orvaschel, 1990; World Health Organization, 2004). Findings from this study revealed that at pretest almost two out of 10 Mexican children were experiencing some symptoms of anxiety or depression. A recent study conducted by Benjet, Borges, Medina-Mora, Zambrano, and Aguilar-Gaxiola (2009) has reported even higher rates of anxiety and depression among Mexican youth, suggesting that these problems escalate over time. It was estimated that about $40 \%$ of Mexican youth had experienced a mental health problem, anxiety was the most common, followed by impulse-control disorders, affective disorders and substance abuse (Benjet, et al., 2009). The later study also found that only $14 \%$ of the adolescents who reported a mental health problem received help. Therefore, research on the prevention of anxiety and depression in developing countries such as Mexico is crucial (Caraveo-Anduaga \& Comenares-Bermúdez, 2002).

Research into universal school-based prevention for anxiety and depression has increased during the last decade yielding promising results (Dozois \& Westra, 2004; Gladstone \& Beardslee, 2009; Neil \& Christensen, 2009; Patel \& Sumathipala, 2001, World Health Organization, 2004). Cognitive-behavioral intervention (CBT) has been regarded as one of the most effective interventions and involves teaching skills at physiological, behavioral and cognitive levels (Barrett, 2000; Compton, Burns, Egger \& Robertson, 2002; Cooper, 2007; Kendall, Chu, Pimentel, \& Choudhury, 2000; Kendall \& Suveg, 20006; Manassis, 2000; Waddell, Godderis, Hua, McEwan, \& Wong, 2004). While several programs have been researched, by and large the most extensively researched program designed to promote children's emotional resilience is the FRIENDS for Life program (Barrett, 2008), a brief CBT intervention (Fisak, Richard, \& Mann, 2011).

Studies of the effectiveness of the FRIENDS for Life program have been conducted at the universal, selective, and indicated level of prevention (i.e, Barrett \& Turner, 2001; Lowry-Webster, Barrett \& Dadds, 2001; Lock \& Barrrett, 2003, Barrett, Farrell, Ollendick \& Dadds, 2006, Stallard, Simpson, Anderson, Osborn \& Bush, 2005). However, only three of them have focused on evaluating the social validity of the program.

Barrett, Shortt, Fox, and Wescombe (2001) conducted the first study evaluating the social validity of the FRIENDS for Life program. In their study they included in the treatment groups 55 children and 12 adolescents with a principal diagnosis of generalized anxiety disorders, separation anxiety disorder or social phobia. Parents, adolescents, and children were surveyed over time about their global satisfaction with the program, acceptability of treatment components, and the completion of homework tasks. Clinical outcome measures were also completed post treatment. Children completed the Revised Children's Manifest Anxiety Scale (RCMAS), parents were asked to complete the Diagnostic Interview Schedule for Children, Adolescents and Parents (DISCAP), and mothers completed the Child Behavior Checklist (CBCL) and the Depression, Anxiety and Stress Scale (DASS). Results indicated a high level of satisfaction with the FRIENDS program and a high completion rate of homework tasks. Children rated cognitive skills as more useful than adolescents did, and adolescents reported behavioral strategy of graded exposure as more useful than other strategies. No significant relationship was found between treatment acceptability and clinical outcomes.

The study by Essau, Conradt and Ederer (2004) evaluated the social validity of the German version of the FRIENDS for Life program implemented as a universal prevention strategy for 208 children ages 9 to 12. Children were asked to complete the Spence Children's Anxiety Scale (SCAS), the Depression subscale of the Revised Child Anxiety and Depression Scale (RCADS), and the FRIENDS Child Social Acceptability Measure translated in German. Parents were asked to complete the FRIENDS Parent Social Acceptability Measure. Results showed that children and their parents were highly satisfied with the program. Children's attendance and completion of homework tasks were very high. Both, children and parents, rated relaxation exercises and thinking helpful thoughts as the more useful skills learnt in the program. Treatment acceptability was correlated significantly with children's clinical outcome.

And lastly, the study by Cooper (2007) evaluated the social validity of the FRIENDS for Life program implemented as a universal prevention program with 29 fourth-grade children, ages nine and 10, from a suburban school in Canada. Social validity questionnaires were developed by the author of this study, students' perception was assessed weekly and upon completion of the program. Students' reported that the program was easy to understand; a bit helpful and about $90 \%$ completed all the homework activities. The overall final evaluation reported that they enjoyed the program, $85.7 \%$ would recommended to others, it was helpful for them, and $71.4 \%$ reported that the program might have been a bit helpful to other children in their classroom. Relaxation techniques, deep breathing and thinking helpful thoughts were the skills found to be more useful; on the contrary, the 6-blocks problem solving plan, recognizing feelings in other, and making others feel good were the skills rated as least useful. Females were found to enjoyed more the program, completed higher percentages of homework tasks, and found the skills learnt more useful and helpful for them and for their classmates, when compared to boys. 
The purpose of the current research was to evaluate the social validity of the Spanish version of the FRIENDS for Life program (called AMISTAD paraSiempre), a social and emotional skills program implemented as a universal school-based strategy for the prevention of anxiety and depression in Mexican primary school-aged children. Specifically, three areas of social validity were examined: (1) The extent to which consumers (students, parents, and teachers) are satisfied with the program, with a detailed assessment of the intervention components, (2) the extent to which there are gender differences in the ratings of techniques and skills learnt in the program, including cognitive and behavioral techniques, and (3) the possible relationship between the level of students' satisfaction with the program and the intervention outcomes, with the hypothesis that a high level of satisfaction is correlated with a high level of improvement in outcome measures.

\section{Method}

\subsection{Participants}

All participants in this study were taken from a larger research project designed to evaluate the effectiveness of the program AMISTAD porsiempre for primary school-aged children in Mexico (Gallegos, Linan-Thompson, \& Stark, 2011). In total, participants were 498 fourth and fifth grade students from four public schools from a city in the Northern part of Mexico. The mean age of participants was $9.78(\mathrm{SD}=0.82), 54.5 \%(\mathrm{n}=271)$ of these students were in grade 4 and $45.5 \%(n=227)$ were in grade $5,49 \%(n=246)$ were boys and $51 \%(n=252)$ were girls. Participants in this study also included the 15 classrooms teachers that implemented the program and 115 parents of children who received the program.

\subsection{Measures}

\subsubsection{Social Validity Measures}

Social validity measures were administered after the completion of the intervention to each of the program consumers: students, parents and teachers.

Social Validity Questionnaire for Children (Barrett, 2005). For this study, the questionnaire was translated into Spanish. The questionnaire was comprised of seven questions. Using a 4-point scale from 1 (a lot/all the time) to 4 (not at all/ nothing at all). The first five questions related to how enjoyable the program was, how much did they learn by doing the program with their classroom friends, how much did they learn about feelings and coping skills, and how often do they use the skills learnt in the program. The sixth question asked students to choose which skills they found more useful from the nine options presented. Finally, the seventh question was an open-ended question for those children that wanted to make any comment.

Social Validity Questionnaire for Parents (Barrett, 2005). For this study, the questionnaire was translated into Spanish. The questionnaire was comprised of eleven questions. The first nine questions used 4-point scale from 1 (a lot/all the time/very useful) to 4 (not at all/ nothing at all/not useful at all). Two of the questions asked how useful they thought positive coping-skills programs were and how important will it be to incorporate a program like this into the school curriculum. Two questions related to how useful the skills were to themselves as parents and how much did they learn about enhancing their child's coping skills. Four questions related to how much they thought their child learnt about feelings and coping skills, how much they thought their child enjoy the program, and how often did their child use the ideas and skills learnt in the program. Question 10 asked parents to choose which skills their child found more useful from the nine options presented. Question 11was an open-ended question that asked to provide any other feedback (positive or negative) that they had.

Social Validity Questionnaire for Teachers (Barrett, 2005). For this study, the questionnaire was translated into Spanish. The questionnaire was comprised of ten questions. The first nine questions used 4-point scale from 1 (a lot/very useful/very easy/very well/very complimentary) to 4 (nothing at all/not at all useful/very difficult/not well at all/not complimentary at all). Two of the questions asked how useful they thought positive coping-skills and resilience programs were for children and young people, how well did the program complement the existing curriculum, and how complimentary was the AMISTAD porsiempre philosophy to the school's overall teaching philosophy. Two questions related to how much did they learn about enhancing resilience in children and adolescents and how easy was to implement the program in their classrooms. Four questions related to how useful was the program for enhancing the resilience of the children in their classrooms, how much did their students learn about feelings and coping skills, and how much they thought their students enjoyed the program. Question 10 was an open-ended question that asked teachers to provide any other feedback (positive or negative) that they had.

\subsubsection{Intervention Outcome Measures}

Three measures were administered collectively to all children to determine the severity of anxiety and depressive symptoms, risk status for anxiety and depression, and coping skills. 
Spence Children's Anxiety Scale(SCAS)(Spence, 1997). The Spanish version was administrated. A self-report measure of anxiety designed for use with children 8-12 years. The SCAS consists of 44 items, 38 of which assess specific anxiety symptoms (e.g. symptoms of social phobia, separation anxiety, panic attack and agoraphobia). The remaining 6 items serve as positive "filter items" in order to reduce negative response bias. Children are asked to rate, on a 3-point scale ranging from never (0) to always (2), the frequency with which they experience each symptom. This measure has showed sound psychometric properties including a reliability coefficient of 0.91 (Bermúdez-Ornelas \& Hernández- Gúzman, 2002). The total score of this measure was used in the current study. Participants scoring 41 or above on the SCAS were considered to be "at risk" for anxiety. This cut-off number was calculated by adding the pretest mean score to $1 \mathrm{SD}$ of the sample of the study by Gallegos, Linan-Thompson and Stark (2011).

Children's Depression Inventory(CDI) (Kovacs, 1981). The Spanish version was administrated. A self-report measure used for depressive symptoms in children aged seven to 17 years. The CDI has 27 items related to the cognitive, affective and behavioral signs of depression. Each item contains three statements, and children select the one statement that best describes them in the past two weeks. Statements within each item are scored according to the severity of children's symptoms: no symptomatology present (0), mild symptomatology (1), or severe symptomatology (2). A total score is calculated by summing the statements chosen by the students. The statement (item nine) that assessed suicidality was removed. The CDI has shown good psychometric properties: a Cronbach's alpha reliability coefficient of 0.94 and a test-retest reliability coefficient of 0.87 , and adequate construct and content validity (Del Barrio, Moreno-Rosset, \& López-Martínez, 1999). Children scoring 15 or above on the CDI were considered to be "at risk" for depression. This cut-off number was calculated by adding the pretest mean score to 1 SD of the sample of the study by Gallegos et al., (2011).

Cuestionario de Afrontamiento (Hernández- Gúzman, 2003). Is a Spanish self-report measure developed and standardized in Mexico to assess coping skills in children aged 6 to 12 years. The scale has 12 items related to child's interpretation and reactions when facing a problem, and the things he or she does to cope and/or solve the problem. Children are asked to rate, on a 3-point scale ranging from never (0) to always (2), the frequency with which they experience each statement. Lower scores reflect a more proactive positive coping. The questionnaire assesses coping responses to situations perceived as stressful and provides information on three factors: active coping, emotional coping, and passive or avoidant coping. The Cuestionario de Afrontamiento has demonstrated adequate psychometric properties including a Cronbach's alpha reliability coefficient of 0.67 (HernándezGuzmán, 2003; Hernández-Guzmán, et al., 2010).

\subsection{Design and Procedure}

A cross-sectional and correlation study was conducted to evaluate the social validity of the intervention.

Before initiating the program participating children completed the intervention outcome measures during the school day (pretest). Teachers and psychologists from the office of Gabinetes de Servicios Educativos (Office of Educational Services), a unit within the Special Education Department of the State, read the instructions and test items aloud to all students, and students answered the questions. Students were informed that all responses were confidential. Classroom teachers from the participating schools were released from their classrooms for a two day training covering the principles and practices of prevention and early intervention. The training provided a step-by-step guide to the intervention program, the AMISTAD para Siempre program (Barrett, 2008a, 2008b).

Following the pretest phase and the training workshop, the program was implemented for 10 consecutive weeks, with one 75 minute session completed once per week. Students were tested at the completion of the $10^{\text {th }}$ session with same intervention outcome measures and a social validity questionnaire. Parents and teachers were also asked to complete the social validity questionnaires after the completion of the program.

\subsection{Intervention Protocol and Materials}

AMISTAD para Siempre (Barrett, 2008a, 2008b), the culturally adapted Spanish version of the FRIENDS for Life program, is a social and emotional program designed to enhance resilience in children. It incorporates physiological, cognitive, and behavioral strategies to assist children in coping with stress and worry. The behavioral component includes the monitoring of feelings and thoughts, out-of-session and mental imagery exposure and relaxation training. The cognitive component teaches children to recognize their feelings and thoughts and the link between them. It also teaches students to identify faulty cognitions and incompatible self-statements, and to elaborate alternative interpretations of difficult situations. Learning techniques include group discussion, hands-on activities, and role-play. Approximately one session is dedicated to learn each of the seven steps represented by the FRIENDS acronym. The Spanish acronym is parallel to the English in terms of the concepts taught. After the introductory session, children start to learn the letter $F$, which stands for "Feeling 
worried?" followed by the letter $R$ "Relax and feel good", $I$ "Inner helpful thoughts", $E$ "Explore solutions and coping plans", $N$ "Nice work; reward yourself", $D$ "Don't forget to practice" and $S$ "Smile and stay calm". Within each session, the teacher uses modeling of the skills, and after the skills are taught, children have opportunities to practice in small groups and debrief with the whole classroom. The program encourages the building of social support groups and respect for diversity. There are two informational sessions for parents with duration of about 1.5 hours each. In these sessions parents learn about the skills and techniques taught in the program, about the importance of family and peer support, and the promotion of the practice of problem solving rather than avoidance of anxiety-provoking situations.

Group leaders received a copy of the AMISTAD para Siempre: Manual para Líderes de Grupo (Barrett, 2008b) that describes the goals and strategies for each session, the desired outcomes, and the specific exercises to be used in meeting these outcomes. Participants from the intervention group received a copy of the AMISTAD para Siempre: Cuaderno de Trabajopara Niños (Barrett, 2008a). The workbook allowed participants to practice the skills. Homework activities provided them with an opportunity to reinforce and generalize the skills and practice with their family.

\subsection{Statistical Analysis}

Means, standard deviations, frequencies and percentages were calculated for each item of the social validity questionnaires. Chi-square analyses were conducted to examine possible gender differences in the skills that students found more useful. Independent sample $t$-tests (alpha level 0.05) were performed for each item of the students' social validity questionnaire in order to examine the presence of gender differences. Pearson correlations (alpha level 0.05) were conducted to examine the relationship between the level of students's satisfaction and the direction of intervention outcomes.

\section{Results}

\subsection{Students' Satisfaction with the AMISTAD Para Siempre Program}

Table 1 displays the students' responses by gender to questions regarding how much they enjoyed the program, how much did they learn, and how often do they practices the ideas and skills learnt in the program. Overall, students evaluated the program as enjoyable and helpful in enabling them to cope with difficult situations; $90 \%$ indicated that they enjoyed the program a lot, 50\% reported that they used the skills learnt all of the time and $44 \%$ of some of the time.

Table 1. Students' means by gender for each of the items of the Social Validity Questionnaire (4 A lot / All the time, 1 Not at All/ Nothing at All)

\begin{tabular}{|c|c|c|c|c|c|c|}
\hline \multirow[t]{2}{*}{ Question } & \multicolumn{3}{|c|}{ Boys } & \multicolumn{3}{|c|}{ Girls } \\
\hline & $M$ & $S D$ & $\mathrm{n}$ & $M$ & $S D$ & $\mathrm{n}$ \\
\hline $\begin{array}{l}\text { 1. How much did you enjoy the FRIENDS } \\
\text { program? }\end{array}$ & 3.83 & .484 & 246 & 3.90 & .344 & 252 \\
\hline $\begin{array}{l}\text { 2. How much did you learn by doing the program } \\
\text { with your classroom friends? }\end{array}$ & 3.58 & 639 & 246 & 3.72 & .524 & 252 \\
\hline 3. How much did you learn about feelings? & 3.64 & .654 & 247 & 3.85 & .465 & 252 \\
\hline $\begin{array}{l}\text { 4. How much did you learn about how to cope } \\
\text { with feeling worried or upset? }\end{array}$ & 3.60 & .719 & 247 & 3.70 & .569 & 251 \\
\hline $\begin{array}{l}\text { 5. How often do you use the ideas and skills } \\
\text { learned in the FRIENDS program? }\end{array}$ & 3.37 & 697 & 247 & 3.48 & .589 & 250 \\
\hline
\end{tabular}

Independent sample t-tests revealed statistically significant gender differences, indicating that girls reported the program as more useful and enjoyable, when compared to boys. Question 1, How much did you enjoy the FRIENDS program $[t(1,498)=-2.11, p=.04]$, Question 2 , How much did you learn by doing the program with classroom friends? $[t(1,498)=-2.69, p=.007]$, Question 3 , How much did you learn about feelings? $[t(1,498)=$ $-4.79, p=.001]$, and Question 5, How often do you use the ideas that you learn in the FRIENDS program? $[t(1,497)$ 
$=-1.99, p=.047]$. No statistically significant differences were found for Question 4 , How much did you learn about how to cope with feeling worried or upset? $[t(1,497)=-1.62, p=.107]$.

Frequencies and percentages of the skills that students found more useful appear on Table 2. On average students endorsed 5.88 items. The two coping skills taught that students found more useful were changing negative thoughts to positive thoughts $(82.2 \%)$ and relaxation exercises $(80.4 \%)$. The two least helpful skills taught were recognizing feelings in yourself $(59.8 \%)$ and helping others to feel good $(42.6 \%)$.

Table 2. Students' ratings of the skills they found more useful

\begin{tabular}{lccc}
\hline \multicolumn{1}{c}{ Skill } & $\begin{array}{c}\text { Overall } \\
\%(n)\end{array}$ & $\begin{array}{c}\text { Boys } \\
\%(n)\end{array}$ & $\begin{array}{c}\text { Girls } \\
\%(n)\end{array}$ \\
\hline Relaxation exercises & $80.4 \%(402)$ & $79.8 \%(197)$ & $81 \%(205)$ \\
Deep breathing & $62.4 \%(312)$ & $65.2 \%(161)$ & $59.7 \%(151)$ \\
Thinking helpful thoughts & $67.4 \%(337)$ & $67.6 \%(167)$ & $67.2 \%(170)$ \\
Changing negative thoughts to & $82.2 \%(411)$ & $85 \%(210)$ & $79.4 \%(170)$ \\
positive thoughts & & & \\
Step plan & $73.4 \%(367)$ & $74.5 \%(184)$ & $72.3 \%(183)$ \\
6-Block problem solving plan & $61.2 \%(306)$ & $60.3 \%(149)$ & $62.1 \%(157)$ \\
Recognizing feelings in yourself & $59.8 \%(299)$ & $57.5 \%(142)$ & $62.1 \%(157)$ \\
Recognizing feelings in others & $79.4 \%(397)$ & $76.5 \%(189)$ & $82.2 \%(208)$ \\
Helping others to feel good & $42.6 \%(213)$ & $42.5 \%(105)$ & $42.7 \%(108)$ \\
\hline
\end{tabular}

Chi-square analysis revealed no statistically significant gender differences in the ratings of skills, the following statistics were reported on table 3 .

Table 3. Chi-square comparison between genders in the ratings of skills.

\begin{tabular}{lcccc}
\hline & $\chi^{2}$ & df & $\mathrm{n}$ & pValue \\
\hline Relaxation exercises & 0.13 & 1 & 401 & $>.05$ \\
Deep breathing & 1.61 & 1 & 311 & $>.05$ \\
Thinking helpful thoughts & 0.01 & 1 & 336 & $>.05$ \\
Changing negative thoughts to helpful thoughts & 2.65 & 1 & 379 & $>.05$ \\
Step plan & 0.3 & 1 & 366 & $>.05$ \\
6-block problem solving plan & 0.16 & 1 & 305 & $>.05$ \\
Recognizing feelings in yourself & 1.08 & 1 & 298 & $>.05$ \\
Recognizing feelings in others & 2.48 & 1 & 396 & $>.05$ \\
Helping others to feel good & 0.01 & 1 & 212 & $>.05$ \\
\hline
\end{tabular}

\subsection{Parents' Satisfaction with the AMISTAD Porsiempre Program}

There were two informational sessions offered for parents during the implementation of the FRIENDS program. The mean number of sessions attended was 1.59 ( $\mathrm{SD}=0.71), 52.6 \%$ of the parents attended to the two sessions, $44.1 \%$ attended only one session, and 3.3\% did not attended to any sessions. Table 4 displays the parents' responses each of the items of the social validity questionnaire. Overall, parents reported that the program was useful for them and for their children; $74 \%$ indicating that they learnt a lot about enhancing their child's coping skills and $87.3 \%$ reported that the program was very useful for enhancing their child's coping skills. 
Table 4. Parents' means for each of the items of the Social Validity Questionnaire (4 Very useful/ Very Important/A lot/ All the time, 1 Not at all Useful/Not at all Important/ Nothing at All/ Not at All)

\begin{tabular}{|c|c|c|c|}
\hline Question & Mean & $S D$ & $N$ \\
\hline $\begin{array}{l}\text { 1. How useful do you think positive coping-skills programs are } \\
\text { in general? }\end{array}$ & 3.97 & .256 & 115 \\
\hline $\begin{array}{l}\text { 2. How useful do you find the FRIENDS program for } \\
\text { enhancing your child's coping skills? }\end{array}$ & 3.87 & .363 & 115 \\
\hline $\begin{array}{l}\text { 3. How important do you think it is that your child's school } \\
\text { incorporates a program like this into the curriculum? }\end{array}$ & 3.97 & .184 & 115 \\
\hline $\begin{array}{l}\text { 4. How much did you learn about enhancing your child's } \\
\text { coping-skills? }\end{array}$ & 3.71 & .528 & 116 \\
\hline $\begin{array}{l}\text { 5. How much do you think your child learned about } \\
\text { understanding feelings in themselves and others? }\end{array}$ & 3.66 & .620 & 116 \\
\hline $\begin{array}{l}\text { 6. How much do you think your child learned about coping with } \\
\text { these feelings? }\end{array}$ & 3.52 & .640 & 115 \\
\hline $\begin{array}{l}\text { 7. How much do you think your child enjoyed the FRIENDS } \\
\text { program? }\end{array}$ & 3.71 & .560 & 114 \\
\hline $\begin{array}{l}\text { 8. How often do you use the ideas (skills) that you learned in the } \\
\text { FRIENDS Parent Sessions? }\end{array}$ & 3.23 & .549 & 114 \\
\hline $\begin{array}{l}\text { 9. How often does your child use the ideas (skills) that they } \\
\text { learned in the FRIENDS program? }\end{array}$ & 3.24 & .519 & 117 \\
\hline
\end{tabular}

Frequencies and percentages of the skills parents found more useful for their children appear on Table 5. On average parents endorsed 5.65 items. The two coping skills taught that parents found more useful for their children were changing negative thoughts to positive thoughts $(75.2 \%)$ and recognizing feelings in yourself (64\%). The two least helpful skills taught were the step plan (34.2\%) and the 6-block problem solving plan (32.5\%).

Table 5. Parents' ratings of the skills their child found more useful

\begin{tabular}{lc}
\hline \multicolumn{1}{c}{ Skill } & Overall \\
& $\%(n)$ \\
\hline Relaxation exercises & $54.7 \%(64)$ \\
Deep breathing & $41 \%(48)$ \\
Thinking helpful thoughts & $63.2 \%(74)$ \\
Changing negative thoughts to positive thoughts & $75.2 \%(88)$ \\
Step plan & $34.2 \%(40)$ \\
6-Block problem solving plan & $32.5 \%(38)$ \\
Recognizing feelings in yourself & $64.1 \%(75)$ \\
Recognizing feelings in others & $57.3 \%(67)$ \\
Helping others to feel good & $59 \%(67)$ \\
\hline
\end{tabular}

\subsection{Teachers' satisfaction with the AMISTAD para Siempre Program}

Table 6 displays means and standard deviations for teachers' responses to each of the items of the social validity questionnaire. Overall, teachers reported that the program was useful for them and for their students; $86.7 \%$ indicating that they learnt a lot about enhancing resilience in children and adolescents and $73.3 \%$ reported that the program was very useful for enhancing resilience in their students. 
Table 6. Teachers' means for each of the items of the Social Validity Questionnaire (4 Very useful/ Very Easy/ Very complimentary/ Very Well/ A lot, 1 Not Useful at All/Very Difficult/Not Complimentary At All/Not Well at All/ Nothing at All)

\begin{tabular}{|c|c|c|c|}
\hline Question & Mean & $S D$ & $N$ \\
\hline $\begin{array}{l}\text { 1. How useful do you think resilience-building programs are for } \\
\text { children and young people in general? }\end{array}$ & 4 & .000 & 15 \\
\hline $\begin{array}{l}\text { 2. How useful do you find the FRIENDS program for } \\
\text { enhancing the resilience of the children in your class? }\end{array}$ & 3.87 & .352 & 15 \\
\hline $\begin{array}{l}\text { 3. How much did you learn about enhancing resilience in } \\
\text { children and adolescents? }\end{array}$ & 3.73 & .458 & 15 \\
\hline $\begin{array}{l}\text { 4. How much do you think the students learned about } \\
\text { understanding feelings in themselves and others? }\end{array}$ & 3.27 & .458 & 15 \\
\hline $\begin{array}{l}\text { 5. How much do you think the students learned about coping } \\
\text { with these feelings? }\end{array}$ & 3.07 & .594 & 15 \\
\hline $\begin{array}{l}\text { 6. How much do you think the students enjoyed the FRIENDS } \\
\text { program? }\end{array}$ & 3.60 & .632 & 14 \\
\hline $\begin{array}{l}\text { 7. How easy did you find to implement the program into your } \\
\text { class or school setting? }\end{array}$ & 3.36 & .633 & 15 \\
\hline $\begin{array}{l}\text { 8. How well did the program complement the existing } \\
\text { curriculum? }\end{array}$ & 3.33 & .617 & 15 \\
\hline $\begin{array}{l}\text { 9. How complementary is the FRIENDS program to the } \\
\text { school's overall teaching philosophy? }\end{array}$ & 3.67 & .488 & 14 \\
\hline
\end{tabular}

\subsection{Relationship between Students' Level of Satisfaction with the Program and Intervention Outcome Measures}

Pearson correlations were performed in order to examine the relationship among the post-test scores of the SCAS, CDI, Cuestionario de Afrontamiento (CA), risk for anxiety, risk for depression, and students' level of satisfaction with the program (See Table 7).

Table 7. Pearson correlations between the level of student satisfaction with the AMISTAD paraSiempre program and the Intervention Outcome Measures

\begin{tabular}{|c|c|c|c|c|c|}
\hline \multirow[t]{2}{*}{ Question } & \multicolumn{5}{|c|}{ Post-test } \\
\hline & SCAS & CDI & $\begin{array}{c}\text { Coping } \\
\text { Skills }\end{array}$ & $\begin{array}{l}\text { Risk for } \\
\text { Anxiety }\end{array}$ & $\begin{array}{c}\text { Risk for } \\
\text { Depression }\end{array}$ \\
\hline $\begin{array}{l}\text { 1. How much did you enjoy the FRIENDS } \\
\text { program? }\end{array}$ & -.033 & $.092 *$ & .078 & -0.69 & .075 \\
\hline $\begin{array}{l}\text { 2. How much did you learn by doing the } \\
\text { program with your classroom friends? }\end{array}$ & .069 & .067 & .025 & .010 & -.004 \\
\hline 3. How much did you learn about feelings? & .046 & $.176^{* *}$ & $.130 * *$ & -.010 & $.194 * *$ \\
\hline $\begin{array}{l}\text { 4. How much did you learn about how to cope } \\
\text { with feeling worried or upset? }\end{array}$ & .073 & $.107 *$ & $.119 * *$ & .072 & .046 \\
\hline $\begin{array}{l}\text { 5. How often do you use the ideas and skills } \\
\text { learned in the FRIENDS program? }\end{array}$ & -.059 & -.037 & -.006 & -.048 & -.027 \\
\hline
\end{tabular}

Note: $* \mathrm{p}<0.05$. $* * \mathrm{p}<0.01$

A statistically significant and positive correlation was found between how much did students enjoy the program and the CDI $(r=0.09, p=.04)$. Positive correlations were also found between how much did students learn about feelings and the CDI $(r=0.18, p=.00)$, the risk for depression $(r=0.19, p=.00)$, and CA $(r=0.13, p=.01)$. How much did students learn about coping with feeling worried or upset reported a statistically significant and positive 
correlation with the CDI $(r=0.107, p=.02)$ and CA $(r=0.12, p=.01)$. No statistically significant correlations were found between the remaining items of the questionnaire and the intervention outcome measures.

\section{Discussion}

The purpose of this study was to evaluate the social validity of the FRIENDS for Life (AMISTAD para Siempre) program implemented as a universal school-based strategy for the prevention of anxiety and depression in Mexican primary school-aged children. Three areas of social validity were examined: (1) The extent to which consumers were satisfied with the program, (2) the extent to which there were gender differences in the ratings of techniques and skills learnt in the program, and (3) the possible relationship between the level of students' satisfaction with the program and the intervention outcomes.

Overall, students rated the AMISTAD para Siempre program as enjoyable and helpful to enable them to cope with difficult situations. Also, most of the parents and teachers were highly satisfied with the program, indicating that it was useful for them and for their children. These findings are similar to results that have been reported with Australian, Canadian and German populations (Barrett et al., 2001; Essau et al., 2004; Cooper, 2007). Thus, suggesting that the program is likely to be well received in a school setting.

Results from this study showed that two coping skills that students found more useful were changing negative thoughts into positive, and relaxation techniques; in contrast to recognizing feelings in you and helping others to feel good. A study from Canada also reported that students found relaxation techniques the most useful (Cooper, 2007). Relaxation might have been recognized as one of the most useful techniques because of the way it was taught; teachers usually give direct and concrete instructions when guiding children to do deep breathing and visualization and used music and relaxation pillows, therefore relaxation could have helped students to experience emotional and physiological benefits relatively soon (Neil \& Christensen, 2009). Other reason could be that children rated other techniques (i.e., coping step plan) as less useful because of their developmental level. Usually older children or teenagers consider abstract techniques more useful, whereas younger children might need more guided practice and visual learning (Barrett, 2008).

In the same way as children, parents also reported that changing negative thoughts into positive $(75.2 \%)$ was the most useful skill learnt, followed by recognizing your own feelings. The two least helpful skills reported by parents were the coping step plan (34.2\%) and the six-block problem solving plan (32.5\%). This may be because these are the two most difficult components of the program that usually required to most modeling and practice at school and home (Barrett, 2008a). Also, the fact that only 44\% of the parents attended the parents' informational sessions could have impacted the results.

In the study from Barrett, Shortt, Fox, and Wescombe (2001) parents's also rated the six-block problem solving plan as the least useful; however, the step plan was rated as the most useful skill, especially when combined with self-rewards (positive reinforcement). In Cooper's (2007) study parents also rated changing negative thoughts into positive the most useful skills, followed by relaxation techniques.

Results from the social validity questionnaires for teachers showed that most of them learnt a lot about enhancing resilience in their students, and that the program was very useful for them. This is a promising finding as schools have been regarded as one of the best settings to implement prevention programs, where a large number of children could be reached during a short period of time (Gladstone \& Beardslee, 2009; Neil \& Christensen, 2009). Thus, opening the possibility of delivering prevention programs as a cost effective strategy in which more children that cannot afford mental health services due to financial or social reasons can now be reached (Costello \& Angold, 1996; Cooper, 2007).

Regarding gender differences in the rating of skills and techniques, this study showed that girls rated the AMISTAD para Siempre program as more useful and enjoyable, when compared to boys. However, no statistically significant differences were found in the rating of specific skills or techniques. Similar results were found in Cooper's study (2007) and might possibly be explained by the fact that during childhood, girls rated higher in their social and emotional skills than boys (Burges, 2006). Girls also tend to outperform men in perceptual speed, verbal fluency, and recall details, and often start their language development earlier than boys (Burges, 2006).

When examining the possible relationship between the level of students' satisfaction with the program and the intervention outcomes, a statistically significant and positive correlation between how much did students enjoy the program and their depressive symptoms as rated by the CDI, The more children enjoyed the program the lower the scores on the depression scale. Positive correlations were also found between how much did students learnt about feelings and their depressive symptoms, risk for depression and coping skills. These are very important findings that pointed out the importance of including social validity as a crucial aspect to take into account when delivering 
and evaluating prevention programs. Some aspects of social validity could also be predictors of intervention outcomes and it would be very interested to booster them during program implementation.

In general, the objectives of the program were reached. Students, teachers, and parents evaluated the program as helpful and satisfying. The study allowed for obtaining knowledge about the consumer's satisfaction of the program and to explore if there were gender differences in the ratings of techniques and skills learnt in the program. According to the results, the study has social validation. The results also suggest that the level of satisfaction and the intervention outcomes are likely to be dependent, meaning that the perceived acceptability of the intervention is a significant predictor of outcome.

\section{Strengths of the Study}

The present study is the first to examine the social validity of the FRIENDS for Life program with Mexican children. In addition to social validity measures, the study has the strength of including outcome measures to explore correlations between children's satisfaction and scores on depression, anxiety and coping skills scales.

Noteworthy is the fact that this study included all consumers: children, parents and teachers. Thus providing a more ecological vision of how the program was received. To our knowledge, this is the only study that has included three consumers when evaluating the social validity of the FRIENDS for Life program.

\section{Limitations and Further Research}

In this study, outcome measures did not reflect a balance for risk and protective factors. This study would have benefitted by evaluating other positive aspects such as resilience, self-esteem, optimism, and quality of peer relationships and explore the relationship between satisfaction with the program and direction of change in protective factors. Most studies that evaluate prevention programs are now including these kinds of measures to provide a more global picture of how the program might work (Dozois\&Westra, 2004; Fisak, Richard, \& Mann, 2011).

Another limitation was the amount of parental involvement during the implementation of the program and measurement time points. Based on resilience and prevention research, parent involvement is critical for program effectiveness and additional benefits for those receiving the program. Further studies should incorporate effective strategies for increasing parental involvement.

Although, all schools were randomly selected from a pool of public schools of similar SES level, no more information besides typical demographic data was collected. This study would have benefitted from information regarding levels of community violence, level of education of parents and marital status, number of family members, and ideally assessing anxiety and depression in parents. Further studies should also gather more information regarding participants in order to generalize the findings and to identify possible predictors of outcome.

Another limitation of this study is that no information was gathered regarding children's attendance and homework task completion. Further studies should include this as there could have an impact in the satisfaction, enjoyment, and acquiring of the skills taught by the program. Follow-up measures should also be incorporated in further research in order to evaluate if gains are maintained.

\section{Conclusion}

This is the first study that evaluates the social validity of the AMISTAD paraSiempreprogram implemented as a universal school-based strategy for the prevention of anxiety and depression in Mexican primary school-aged children. Results from this study are promising and showed that Mexican children as well their teachers and parents regarded the AMISTAD paraSiempreprogram as useful and enjoyable. The skill that students and parents found more useful was changing negative thoughts into positive. Girls reported the program as more useful and enjoyable than boys, however there were no differences found in the ratings of scales. Positive correlations were found between some items of the social validity measure and symptoms of depression, anxiety and coping skills; thus, pointing out an important research area to explore. Further studies should include more positive measures and should increase parental involvement.

\section{References}

Barrett, P.M. (2000). Treatment of childhood anxiety: Developmental aspects. Clinical Psychology Review, 20, 479-494. http://dx.doi.org/10.1016/S0272-7358(99)00038-0

Barrett, P. (2005). Support Materials for the FRIENDS program. Brisbane, Australia: Pathways Health and Research Centre. 
Barrett, P. (2008a). AMISTAD para Siempre: Cuaderno de Trabajo para Niños [FRIENDS for Life: Workbook for children]. Brisbane, Australia: Australian Academic Press.

Barrett, P. (2008b). AMISTAD para Siempre: Manual para Líderes de Grupo [FRIENDS for Life: Manual for Group Leaders]. Brisbane, Australia: Australian Academic Press.

Barrett, P., Farrell, L. J., Ollendick, T. H., \& Dadds, M. (2006). Long-term outcomes of an Australian universal prevention trial of anxiety and depression symptoms in children and youth: An evaluation of the FRIENDS program. Journal of Clinical Child and Adolescent Psychology, 35(3), 403-411.

Barrett, P., Shortt, A.L., Fox, T.L., \& Wescombe, K. (2001). Examining the social validity of the FRIENDS treatment program for anxious children. Behaviour Change, 18, 63-77. http://dx.doi.org/10.1375/bech.18.2.63

Barrett, P., \& Turner, C. (2001). Prevention of anxiety symptoms in primary school children: Preliminary results from a universal school-based trial. The British Journal of Clinical Psychology, 40, 399-410. http://dx.doi.org/10.1348/014466501163887

Benjet, C., Borges, G., Medina-Mora, M.E., Zambrano, J., \& Aguilar-Gaxiola, S. (2009). Youth mental health in a populous city of the developing world: Results from the Mexican adolescent health survey. Journal of Child Psychology and Psychiatry, 50, 386-395. http://dx.doi.org/10.1111/j.1469-7610.2008.01962.x

Bermúdez-Ornelas, G., \& Hernández- Gúzman, L. (2002).La medición de la fobia específica en niños y adolescentes [Measuring specific phobia in children and teenagers]. Revista Mexicana de Psicología, 19, $119-225$.

Burges, L. (2006). Diferencias mentales entre los sexos: innato versus adquirido bajo un enfoque evolutivo [Mental differences between genders:innate versus acquired under a evolutive approach]. Ludus Vitalis, 14, 43-73. Retrieved from http://www.ludusvitalis.org/textos/25/25_burges.pdf

Caraveo-Anduaga, J. J., \& Comenares-Bermúdez, E. (2002). Los trastornos psiquiátricos y el abuso de substancias en México: Panorama epidemiológico [Psychiatric disorders and the abuse of substances in México]. Salud Mental, 25, 9-15. Retrieved from http://redalyc.uaemex.mx/pdf/582/58222502.pdf

Compton, S. N., Burns, B. J., Egger, H. L., \& Roberston, E. (2002). Review of the evidence base for treatment of childhood psychopathology: Internalizing disorders. Journal of Consulting \& Clinical Psychology, 70, 1240-1266. http://dx.doi.org/10.1037//0022-006X.70.6.1240

Cooper, J. A. (2007). Canadian Social Validity Evaluation of the FRIENDS School-Based Universal Anxiety Prevention Program.(Master's thesis, University of Manitoba, Canada). Retrieved from http://umanitoba.ca/graduate_studies/

Costello, E. J., \& Angold, A. (1995). Epidemiology. In J.S. March (Ed.), Anxiety disorders in children and adolescents (pp. 109-122). New York: Guilford Publications.

Del Barrio, M. V., Moreno-Rosset, C., \& López-Martínez, R. (1999).The Children's Depression Inventory (CDI: Kovacs, 1992) in a Spanish sample. Clínica y Salud,3, 263-272.

Dozois, D. J. A., \& Westra, H. A. (2004). The nature of anxiety and depression: Implications for prevention. In D.J.A. Dozois\& K.S. Dobson (Eds.), The prevention of anxiety and depression: Theory, research and practice. (pp. 9-41). Washington, DC: American Psychological Association.

Essau, C. A., Conradt, J., \& Ederer, E. M. (2004). Anxiety prevention among school children. Versicherungsmedizin, 56(3), 123-130.

Fawcett, S. B. (1991). Social Validity: A note on methodology. Journal of Applied Behavior Analysis, 24, 235-239. Retrieved from http://www.ncbi.nlm.nih.gov/pmc/articles/PMC1279568/pdf/jaba00020-0061.pdf

Fisak, B. J., Richard, D., \& Mann, A. (2011). The prevention of child and adolescent anxiety: A meta-analytic review. Prevention Science, 12, 255-268. http://dx.doi.org/10.007/s11121-011-0210-0

Foster, S. L., \& Mash, E. J. (1999). Assessing social validity in clinical treatment research: Issues and procedures. Journal of Consulting and Clinical Psychology, 67, 308-319.

Gallegos, J., Linan-Thompson, S., \& Stark, K. (2011). Preventing Childhood Anxiety and Depression: Testing the Effectiveness of a School-Based Program in Mexico. Manuscript accepted with revisions.

Gladstone, T., \& Beardslee, W. R. (2009). The prevention of depression in children and adolescents: A review. $L a$ Revue Canadienne de Psychiatrie, 54(4), 212-221. 
Hernández-Gúzman, L. (2003). Escala de afrontamiento (versión infantil). Proyecto de investigación DGAPA IN-302600, evaluación y categorización de los trastornos de ansiedad en niños y adolescentes [Coping scale (child version).Research project DGAPA IN-302600, evaluation and classification of anxiety disorders in children and teenagers] . México: Universidad Autónoma de México.

Hernández-Guzmán, L., Bermúdez-Ornelas, G., Spence, S. H., González, M. J., Martínez-Guerrero, J. I., Aguilar, J., \& Gallegos, J. (2010). Versión en Español de la Escala de Ansiedad para Niños de Spence (SCAS) [Spanish version of the Spence Children's Anxiety Scale]. Revista Latinoamericana de Psicología, 42, $13-24$.

Kashani, J. H., \& Orvaschel, H. (1990). A community study of anxiety in children and adolescents. American Journal of Psychiatry, 147(3), 313-318.

Kendall, P. C., Chu, B. C., Pimentel, S. S., \& Choudhury, M. (2000). Treating anxiety disorders in youth. In P. C. Kendall (Ed.), Child and Adolescent Therapy: Cognitive-Behavioral Procedures (pp. 235-287). New York, NY: The Gilford Press.

Kendall, P. C., \& Suveg, C. (2006). Treating anxiety disorders in youth. In P.C. Kendall (Ed.), Child and adolescent therapy (pp. 243-296). New York, NY: The Guildford Press.

Kovacs, M. (1981). Inventario de Depresión Infantil. Madrid, España: TEA Ediciones.

Lowry-Webster, H. M., Barrett, P., \& Dadds, M. R. (2001). A universal prevention trial of anxiety and depressive symptomatology in childhood: Preliminary data from an Australian study. Behaviour Change, 18, 36-50. doi:10.1375/bech.18.1.36

Lock, S., \& Barrett, P. (2003). A longitudinal study of developmental differences in universal preventive intervention for child anxiety.Behavior Change, 20, 183-199. http://dx.doi.org/10.1375/bech.20.4.183.29383

Manassis, K. (2000). Childhood anxiety disorders: Lessons from the literature. Canadian Journal of Psychiatry, 45, 724-731. Retrieved from http://publications.cpa-apc.org/browse/sections/0

Neil, A. J., \& Christensen, H. (2009). Efficacy and effectiveness of school-based prevention and early intervention programs for anxiety.Clinical Psychology Review, 29,208-215. http://dx.doi.org/10.1016/j.cpr.2009.01.002

Patel, V., \& Sumathipala, A. (2001). International representation in psychiatric journals: A survey of 6 leading journals. British Journal of Psychiatry, 168, 406-409.

Shortt, A., Barrett, P., \& Fox, T. (2001). Evaluating the FRIENDS Program: A Cognitive-Behavioral group treatment for anxious children and their Parents. Journal of Clinical Child Psychology, 30(4), 525-535.

Shwartz, I. S., \& Baer, D. M. (1991). Social validity assessments: Is current practice state of the art? Journal of Applied Behavior Analysis, 24, 189-204. http://dx.doi.org/10.1901/jaba.1991.24-189

Spence, S. H. (1997). Structure of anxiety symptoms in children: A confirmatory factor-analytic study. Journal of Abnormal Psychology, 106, 280-297. http://dx.doi.org/10.1037/0021-843X.106.2.280

Stallard, P., Simpson, N., Anderson, S., Carter, T., Osborn, C., \& Bush, S. (2005). An evaluation of the FRIENDS programme: A cognitive behaviour therapy intervention to promote emotional resilience. Archive of Disease in Childhood, 90, 1016 -1019. http://dx.doi.org/10.1136/ads.2004.068163

Waddell, C., Godderis, R., Hua, J., McEwan, K., \& Wong, W. (Eds.). (2004). Preventing and Treating Anxiety Disorders in Children and Youth (Report No.1). Vancouver, Canada: University of British Columbia, Children's Mental Health Policy Research Program.

Wolf, M. M. (1978). Social Validity: the case for subjective measurement or how applied behavior analysis is finding its heart. Journal of applied behavior analysis, 11, 203-214. http://dx.doi.org/10.1901/jaba.1978.11-203

World Health Organization. (2004). Prevention of mental disorders: Effective interventions and policy options. Geneva: WHO.

\section{(cc) $\mathrm{Br}$}

This work is licensed under a Creative Commons Attribution 3.0 License. 